\title{
The Natural Ontological Attitude in a Hermeneutic Context
}

\author{
Dimitri Ginev
}

Zukunftskolleg, University of Konstanz

My aim in this paper is to re-examine Arthur Fine's concept of the natural ontological attitude. Whereas earlier critical interpretations focus on the compatibility of NOA with scientific realism, I argue that Fine's conception is to be recast in terms of an interpretative theory of scientific research. Specifically, I make the case that the hermeneutic reformulation of NOA is unavoidable when at stake are the issues of the structural, conceptual, and experimental articulation of scientific domain. The paper concludes by considering the formation of local epistemological positions in the research process.

Keywords: the natural ontological attitude, hermeneutic fore-structure of scientific research, characteristic hermeneutic situation, proto-normativity, local epistemological positions

\section{Introduction}

Arthur Fine argues that there is an anthropologically quasi-universal attitude that is formed and developed in a natural manner. Fine is less preoccupied with the question of whether the predicate 'natural' in the NOA is to be tied to a kind of evolutionary and/or cognitive naturalism than with the methodological functions this attitude serves in scientific research. Since Fine does not offer a naturalist framework that circumscribes the methodological line of reasoning, his conception of NOA is distinguished by a kind of methodological anti-naturalism. In commenting on the status of the natural ontological attitude, Fine places emphasis entirely on the primary ontic assumptions and intuitions of "more homely truths" that play crucial role in getting scientific knowledge. These assumptions and intuitions are

Corresponding author's address: Dimitri Ginev, Zukunftskolleg, University of Konstanz, Fach 216, D-78457 Konstanz, Germany. Email: Dimitri.Ginev@uni-konstanz.de. 
"methodologically natural" as compared with the "non-natural" methodologies imposed externally through epistemological interpretations of scientific research. The natural ontological attitude counsels the participants in scientific research to accept the results of their practices as true. More specifically, NOA commits the scientists to the world as it gets articulated in scientific research qua a mode of being in the world. Thus considered, the conception of NOA can be tied to various philosophical traditions. Fine strongly rejects any connection with the (prima facie closest to his views) tradition of phenomenological investigation of the pre-predicative natürliche Einstellung. The insistence on transcendental subjectivity seems to be at odds with his radical anti-essentialism. However, Fine's scenario of how NOA operates in scientific research cannot avoid appealing to transcendental arguments.

It is the implementation of such arguments without admitting an autonomous transcendental position that makes the conception of NOA akin to the tradition of pragmatism, especially to Peirce's philosophy. Moreover, NOA is not a passive (contemplative) but rather a practical-instrumental attitude. By implication, pragmatism/pragmaticism seems to be a "natural ally" of the NOA conception. In fact, the unique combination of the concept of 'true community of researchers', the logic of abduction, and the specific brand of realism in Peirce's philosophy implies a constellation of assumptions similar to NOA. Interestingly enough, Peirce ascribes these assumptions not to the particular participants in scientific research but to the "community that is ordered by discovery" and freed from ideological interests. The trans-subjective self-control of the inquiry into truth is what vindicates Peirce's pragmaticism. The analogy with Peircean pragmatism can help one to pay closer attention to the trans-subjective character of NOA. Yet pragmatism, I believe, is not the philosophy which can provide the resources for scrutinizing this character. In Peirce's doctrine of how individual inquirers are incorporated into the scientific community, the priority of the trans-subjectivity follows simply from the ideal-regulative status of this community. (It is another question that Peirce in his political philosophy and doctrine of positive freedom champions the transformation of the ideal into real community. ${ }^{1}$ ) Appealing to an ideal (quasi-transcendental) community would restore again that spirit of essentialism which Fine repudiates with quite good arguments. To sum up, a "more philosophical" reading of NOA would be only justified if the trans-subjectivity of this attitude gets advocated from a radically non-essentialist viewpoint. From such a viewpoint, one ought to address the NOA's self-sufficiency which makes any external epistemological interpretation of scientific research superfluous.

My aim in this paper is to broaden Fine's conception of the natural onto-

1 See on this point (Ward 2001). 
logical attitude by reformulating its central claims in terms of a view about the interpretative fore-structuring of scientific research. I am going to criticize some deficiencies of NOA's original formulation by appealing to a hermeneutic theory that will be unfolded step by step in the discussion to follow. Fine focuses on the issue of how NOA enables scientists' interpretative practices. Nonetheless, he is convinced that science's interpretative dimension is not in need of a hermeneutic elucidation. More specifically, Fine makes the case that the philosophically minimal characterization of NOA's interpretative character is to dispense with an interpretative-reflective strategy about the specificity of science en bloc. He $(1996,148)$ goes on to argue that a "hermeneutic understanding of science has to be gained from the inside. It should not be prefabricated to meet external, philosophical specifications. There is, then, no legitimate hermeneutical account of science, but only a hermeneutical activity that is a lively part of science itself."

To be sure, this statement is in full agreement with Fine's anti-essentialism which will be commented on later. Yet in attributing an externalist schematism to the hermeneutic enterprise, Fine seems to misunderstand the very idea of a hermeneutics of scientific research. Like the conception of NOA, the latter has no prior extra-scientific commitments. Roughly speaking, an interpretative theory of science's practices of reading experiments, experimental systems, instruments, measurements, theoretical concepts, models, diagrams, differential equations, etc. is predicated on a double hermeneutics that avoids any superimposition of interpretative or explanatory schemes on science. The scenarios of studying science in the perspective of double hermeneutics aim at an interpretative understanding of the ways in which contextual meaning of scientific objects becomes interpretatively constituted. ${ }^{2}$ These scenarios oppose the ideas of social or rhetorical construction of scientific knowledge's objectivity. The main point of the interpretative theory of science is that the process of reading in scientific research constitutes meaningful scientific objects, thereby articulating the domains of research. Like the conception of NOA, the hermeneutics of scientific research is thoroughly deflationist. Both of them opt for deflationism over a priori explanations of scientific rationality. In both cases, one is engaged in undercutting the ideas that science has a metaphysical essence and an ultimate goal. (However, the hermeneutics of scientific research argues in addition that despite the lack of an essence and a goal science manages to create its cognitive specificity within its interpretative spaces of representation. The topic of this specificity is not at stake in the conception of NOA.)

Thus, Fine's charge can be resisted. In what follows I will be concerned

2 On various aspects of this double hermeneutics as applied to science's understanding see, (Kockelmans 1993), (Eger 2006), (Ginev 1997). 
with showing that Fine's reasons for adopting NOA coincide essentially with the reasons for introducing a hermeneutic theory of scientific research that does not violate the rule to gain a philosophical understanding from the inside. ${ }^{3}$ My contention is that there is a rationale for a hermeneutic rereading of NOA. On the account I am going to suggest, the core of the natural ontological attitude consists of an initial (i.e. pre-epistemological) interpretation of the world that operates also within science's interpretative practices and their spaces of representation.

Assigning a pre-epistemological character to the "core position" invalidates the critical argument that there is a lack of resources in Fine's conception to demonstrate the independence of the natural ontological attitude from the tenets of scientific realism. Unless one attributes to NOA minimal commonsensical (i.e. rudimentary realist) epistemological assumptions, NOA is not a proto-realist position. Moreover, the conception under discussion would fail to avoid a self-defeating character, if one goes on to attribute a primitive realism to NOA. In this case, the conception would have had to aver two claims that contradict each other: (a) NOA is simply an explication of a realist position that is naturally formed and developed; and (b) NOA opposes each kind of realism since every realist position stems from an imposition of external philosophical interpretations on the naturally developed ontological assumptions.

On a further claim that will be scrutinized in the remainder, NOA gets circumscribed by contextually employed "readable technologies" of scientific research, whereby it retains its pre-epistemological status in the research process. Yet the role of the natural ontological attitude is by no means to be restricted to transference of what intuitively is "more homely true" from everyday experience to science. From a hermeneutic point of view, in scientific research NOA plays a much more active role by fore-structuring the formation of local epistemological positions and the articulation of scientific domains. The formation of such positions is entangled in the structural, conceptual, and experimental articulation of scientific domains. On a main hermeneutic tenet, the articulation of a scientific domain oscillates between the de- and re-contextualization of objects of inquiry. The balance between them (established as a tendency of articulation) defines a characteristic hermeneutic situation of scientific research. In science the natural ontological attitude is always circumscribed by such a situation.

The first step in working out this thesis requires to introducing the concepts of a hermeneutic fore-structure and a characteristic hermeneutic situation of scientific domain's articulation. I will address this task in two sections to come. This job accomplished, I will turn in the final section to the

3 On Fine's reasons for adopting NOA see also (Rouse 1988). 
hermeneutic reformulation of NOA. It is my contention that such a reformulation opens the avenue for an interesting dialogue between the analytical and the Continental philosophy of science. Finally, the issue of the double status of NOA in the hermeneutics of scientific practices will be briefly addressed.

\section{Preliminary Hermeneutic Considerations: Scientific Practices and Possibilities of Research}

On the so-called semantic view, theories are collections of models (mathematical structures of one or another sort). A radical version of this view postulates that theories' structures are described only up to isomorphism. The determinism about theories' semantic interpretation implied by this version has several unwelcome epistemological consequences. For instance, it prevents one from taking into account non-structural factors in the interpretation of scientific theories. To avoid such consequences requires a weakening of semantic structuralism. There are a growing number of proposals in this regard. ${ }^{4}$ In my view, however, the philosophically most interesting way to accomplish this job was suggested by Bas van Fraassen many years ago. In Scientific Image he addresses the task of weakening semantic structuralism by making room for a hermeneutic openness in theory construction. $\mathrm{He}(1980,55-58)$ devises a hermeneutic circle that takes place in the mathematical saving of phenomena. Notoriously, van Fraassen claims that experimentation (as a selective construction of data models) is the continuation of theory construction by other means. In this continuation a specific kind of interplay between theory's interpretation and the construction of relational structures of data (appearances) takes place. This interplay aims at establishing a balance between the range of theory's semantic models (which should be sufficiently wide to delineate the empirical area of theory's validity) and the narrowing down of this range so as to give the theory greater empirical content. It is this interplay that gets addressed in terms of a hermeneutic circularity.

Three steps are to be distinguished in van Fraassen's way of specifying science's intra-theoretical hermeneutic circle. He admits that it would be strange if scientific theories described the phenomena in different terms from the trans-phenomenal rest of the world they describe. By implication, he asserts that it is impossible to interpret science by dividing its language into observable and non-observable parts since they are involved in a co-

\footnotetext{
${ }^{4}$ A case in point is the search for semantic models that contain modal information. Katherine Brading (2011, 58-59) calls the models which contains a range of possible trajectories for the system, specifying what the system can and must do according to the theory, "generic models".
} 
interpretative relationship. This is the argument of constructive empiricism for making use of the figure of hermeneutic circle in revealing science's linguistic homogeneity. Thinking in terms of an interpretative circularity puts forward an alternative to drawing an essential (philosophically significant) line between the phenomenal and the trans-phenomenal by means of an observable/unobservable distinction of science vocabulary. ${ }^{5}$ A leading role in handling circularity of saving phenomena plays the kind of holism championed by constructive empiricism: The phenomena are saved when they are exhibited as fragments of a larger unity that does not have a surplus of meaning beyond the meaning of phenomena. Accordingly, the hermeneutic circle is defined as an inter-translatability of particular descriptive statements and the theory's semantic model(s) in which the validity of these statements become authenticated. In other words, this is the inter-translatability which underlies the semantically justified empirical adequacy of a scientific theory.

The hermeneutic circle in question is an intra-theoretical one because it is the theory that draws the demarcation between the phenomenal and the trans-phenomenal. The demarcation is not drawn by means of an external philosophical conception as this is the case of the vocabulary distinction (put forward, in particular, by Carnap). Through its semantic models the theory discloses certain areas as observable. The next step van Fraassen undertakes is to figure out how to avoid a collapse of this hermeneutic circle into a vicious circularity. For this purpose, he makes the case that the intertranslatability opposes the post-empiricist thesis of the theory-dependence of observation in a radical manner. The following passage is quite illuminative in that regard:

To delineate what is observable (within a theory) we must look to that same theory for that is also an empirical question. This might produce a vicious circle if what is observable were itself not simply disclosed by theory, but rather theory-relative or theory-dependent. It will already be quite clear that I deny this: I regard what is observable as a theoryindependent question. (van Fraassen 1980, 57)

Since observation is a special subspecies of measurement, the doctrine of the intra-theoretical hermeneutic circle should be integrated in the general theory of measurement. This is the final step in van Fraassen's discussion. Only measurable phenomena are meaningful in scientific research. The circle is between the theoretical context in which one identifies what counts as a measurement of a certain property and the disclosing of measurable phenomenon in that context. Granted that an acceptable theory has at least one model that all measurable phenomena fit inside, the context is

${ }^{5}$ See (van Fraassen 1976). 
provided by theory's models. The theoretical context of measurement is not behind the measurable phenomena. As a disclosing whole, it has no meaning beyond the interplay of theory's interpretation and the construction of relational structures of phenomena.

Short after van Fraassen developed his view about the hermeneutic circle in theory construction Patrick Heelan (1983) advanced much broader interpretative doctrine of scientific research. ${ }^{6}$ His point of departure was the claim that the semantic interpretation of theory's mathematical structure is not only complemented by various kinds of non-structural interpretation but it is involved in an open hermeneutic circularity that transcends from the very outset theory construction. On this account, theory construction is a particular (cluster of) practice(s) that does not enjoy a privileged status among the totality of practices. Thus, he went on to transform the intratheoretical circle into an interpretative circularity that embraces all practices of scientific research. Heelan defended this transformation by treating each of these practices as a readable technology. ${ }^{7}$ Scientific research is a process of employing readable technologies that create particular spaces of representation in which the objects of inquiry take place. In Heelan's perspective, interpretative practices (i.e. practices qua readable technologies) of scientific research get distinguished by a potentiality to constitute relevant objects of inquiry. ${ }^{8}$

Following this thread, one is to state that a hermeneutic doctrine of scientific research is entitled to portray the process of research in terms of changing configurations of interrelated practices. ${ }^{9}$ Scientific research is predicated on a dynamics of reticulated routine practices of constructing and calibrating instruments, designing and replicating experiments, preparing reports on observations, applying formal techniques for a graphical description, developing systems of differential equations, controlling experimental systems, measuring control parameters of experimental systems, constructing various kinds of models, devising thought experiments, representing systems' dynamics through phase diagrams, creating computer simulations, and so on. Each particular configuration defines a situation in the development of this process. In operating as a readable technology a scientific

${ }^{6}$ In the 1980's Patrick Heelan championed the idea that hermeneutics is to be applied not (only) to studying the argumentative structure of scientific publication (i.e. as a counterpart to the rhetoric of science) but most of all to studying the production of theoretical and empirical results (science's cognitive content) within practices of "normal-scientific life-worlds". See, for instance, (Heelan 1989).

7 See (Heelan 1983, 181-204).

${ }^{8}$ On Heelan's most elaborated version of scientific research's hermeneutic circularity see (Heelan 1998).

9 On a detailed discussion of this theory see (Ginev 2011). 
practice opens a space of representation of what gets read. Since the practices involved in a configuration work in concert, there is no space of representation existing independent of the situation's other spaces. ${ }^{10}$ One is to state that in a situation of scientific research, because of practices' reticulated interrelatedness, the reading process takes place in deferring spaces of representation. The meaning of what is represented and read in a given space is always already deferred in the spaces of other practices with which the current readable practice is interrelated. As a consequence, the objects of inquiry are scattered in these spaces. Yet the scattering occurs in a projected horizon of possibilities for articulation of a research domain. What is read and represented in deferring spaces of representation is fore-structured by the projection of a horizon of possibilities. Due to the fore-structuring of domain's articulation, the formal, the theoretical, and the empirical objects of inquiry are potentially homogeneous entities, despite their dissemination in spaces of reading/representation. Before spelling out this view, let me briefly address the concept of domain's articulation.

The articulation has three main dimensions which should be dubbed (a) the structural, (b) the conceptual, and (c) the experimental articulation. Domain's structural articulation is the process of interpreting the mathematical structure of domain's theory by means of semantic models. The conceptual dimension refers to the articulation of data-models for domain's theoretical concepts. Finally, by experimental articulation I mean the experimentally verified theoretical predictions. This dimension of domain's articulation is a function of the ongoing independent testing of domain's theory. The outcome of the experimental articulation is the growing number of empirical states of affairs identified by means of domain's theory (or, more precisely, by means of experiments figured out and licensed by that theory). To be sure, the three modes of articulation are only analytically separable. In fact, they are working in concert, and each well-substantiated reconstructive model of science has to reveal their forms of interdependence.

ad (a) In opposing scientific realism, the contemporary structuralist tendency in philosophy of science promotes a shift away from objects to the structures. ${ }^{11}$ Yet leading champions of this tendency still insist that the former are not "dissolved" but rather "embedded" in the latter. With regard to this embeddedness, it seems to me appropriate to say that the structural articulation of a domain brings into being a range of meaningful (mathematical, hypothetical-theoretical, and empirically verified) entities that exist within the situation's contextualized spaces of representation. Per definitionem, a space of representation is a space in which the structure and objects

${ }^{10}$ See (Rheinberger 1997, 91-95).

${ }^{11}$ See, for instance, (French and Ladyman 2011). 
are united. Examples of such spaces which represent "structures with embedded objects" are a phase diagram, a statistical ensemble of experimental results, network of quantifiable data achieved by calibrated instruments, an algebraic model of measurements, a particular solution of a system of differential equations, or a semantic model of a theory's formalism. To make use of Nelson Goodman's celebrated distinction, in all of these cases one has in mind 'representation as' and not 'representation of'. In scientific research, representing something as a data-model, a computer simulation, a phase diagram, and so on, amounts to reading it within the respective spaces of representation. In representing meaningful entities, one constantly reads them within the horizon projected by the situation's configuration of practices.

ad (b) Each theoretical concept is "inscribed" on a horizon of possible data-models that can take place in various situations of the research process. The theoretical concepts are always represented by data-models. (There is a belief in the existence of a trans-phenomenal entity involved in such a concept. Thus, at the end of 1920 s the dominant research community in quantum mechanics believes that the domain's theoretical concepts refer to objects whose physical observables can be expressed by self-adjoint operators. Though nobody at that time was able to demonstrate the physical significance of these operators, the belief in quantum-mechanical objects expressible via the theory of group representation by linear transformations remained intact. It was this belief that guided the search for datamodels of the theoretical concepts.) The ongoing instantiation of a theoretical concept by data in the research process transforms progressively a trans-phenomenal entity into a manifold of data-models. Yet this transformation is an infinite process since the content of a theoretical concept cannot be represented by a finite set of data-models. By implication, these concepts possess a twofold existence-as "inscriptions" on projected horizons related to "beliefs in trans-phenomenal entities being instantiated by empirical models" and as a growing instantiation of the objects (which the theoretical concepts refer to) by means of data-models. The content of these concepts do not exist beyond (or independently of) the circularity of projected horizon and actual instantiations. ${ }^{12}$ This view does not depend on the ontological assumptions about the theoretical terms' content. One may assume that what the theoretical concepts express are structures all the way dawn. Or alternatively, one may subscribe to a kind of "reist ontology" (after the doctrine of "reism" which claims that the category of object is the only ontological category), thereby arguing that all structures are reducible to intrinsic properties of objects. Of course, there is a wide spectrum of intermediate kinds of ontology. Regardless of the ontology, however, one assumes

\footnotetext{
${ }^{12}$ See (Ginev 2008).
} 
that the theoretical concepts have meaning only within the aforementioned interpretative circularity. The metaphysical attitudes brought into play by all of these sorts of ontological assumptions are irrelevant to the conceptual articulation of a scientific domain.

ad (c) The experimental articulation of a domain is also involved in a sui generis hermeneutic circularity. It is projected upon a horizon of theoretical predictions whose gradual experimental testing extends or narrows down the very horizon. The experimental outcomes articulate the domain within a projected horizon of possible (empirically verifiable) states of affairs (theoretical predictions). Thus, the independent testing of theoretical predications sets up own interplay of projection and appropriation of possibilities of domain's articulation.

The three dimensions of domain's articulation premise an "original" articulation of the world achieved by the natural ontological attitude in accordance with (what Fine calls) "homely truths". Yet both types of articulationthe pre-scientific and the three-dimensional scientific one-run as interpretative processes within horizons of understanding the world qua projected possibilities. There is no primary attitude toward the "external world" hidden behind the interpretative articulation of horizons of possibilities. By the same token, there is no elementary referential semantics that articulates the world "more primordially" than the interpretative-contextual articulation within the world. Like the attitudes of contextual reading/representing involved in a domain's articulation, the NOA is an interpretative and practical attitude. I will return to this point in the final section.

Let me now resume the discussion of the hermeneutic perspective on science. It is the interrelatedness of practices of inquiry that projects an open horizon of possibilities (possible semantic models, data-models, and experimental outcomes) for the research process. The point here is that the projection is not a mental (individual or collective) act, but something that is generated by the co-references and the mutual reinforcement of scientific practices, each of them distinguished by a particular space of representing and reading objects of inquiry. (Tentatively speaking, the natural ontological attitude "works" within the deferring spaces of representation/reading. NOA regulates the configurations of practices, being at the same time specified as interpretative stance by these configurations.) What get projected are possibilities of representing and reading scientific objects within integral spaces of configured practices. The projected horizon is always already transcendent with respect to what becomes actualized in each particular situation of this process. The research process in a given domain has always a "potentiality for being". Accordingly, the ongoing appropriation of these possibilities remains constantly open. Through this appropriation a progressive artic- 
ulation of a domain (in the aforementioned three dimensions) comes into being. The continuous actualization of possibilities and the concomitant articulation of a domain of research objects are characterized by anticipations, expectations and orientations assigned to the community which carries out the research process. Like the routine practices of research, the possibilities upon which the research process is projected do not have an autonomous reality per se. Any suggestion of possibilities projected independently of their appropriation within spaces of representation/reading would imply essentialism of the same sort which authors like van Fraassen, Fine, and Rorty try to overcome in order to combat the inflation of metaphysics in the philosophy of science.

Against the background of the foregoing considerations, let me introduce now the concept of the hermeneutic fore-structure of scientific research. This concept comes to the fore as a result of the efforts to specify the circular nexus of understanding and interpretation with regard to the constitution of scientific objects and the articulation of domains of research. Roughly speaking, those who are involved in the research process of a given domain understand the domain in the first place as possibilities (of structural, conceptual, and experimental articulation) that can be appropriated. One appropriates the possibilities by employing readable technologies. In doing so, one articulates the domain of research by actualizing possibilities of making readable what is under investigation. Per definitionem, interpretation is appropriation of possibilities by means of readable technologies, whereby the actualized possibilities articulate the domain of research. A particular aspect of this articulation is the constitution of new structures/objects of inquiry. (I again intentionally refrain from taking a position here with regard to the debate on whether structures have an ontological priority over objects, or vice versa.) Understanding (the domain of research as a horizon of possibilities) and interpretation (articulation through readable technologies) are in constant interplay during the domain's potentially infinite articulation. It is this interplay that I will call a hermeneutic fore-structure of a domain's (three-dimensional) articulation.

The hermeneutic fore-structure is projected in such a manner on the research process that it enables the participants in that process (i) to "see in advance" what gets articulated as objects integrated in spaces of representation; (ii) to "have in advance" domain's thematic objects as "readable entities"; and (iii) to "grasp in advance" the outcomes of independent tests as "something ready-to-hand" by means of calibrated instruments and procedures of measurement. The common component "in advance" refers to possibilities that can be appropriated in the structural, conceptual, and experimental articulation. Following the established terminology of philosophical 
hermeneutics, these three aspects of the hermeneutic fore-structure are to be respectively dubbed fore-sight, fore-having, and fore-conception. To reiterate, these aspects are to be clearly differentiated by having recourse to the ongoing appropriation of the projected horizon. The unity of them provides the unity of domain's three-dimensional articulation. ${ }^{13}$ It is the hermeneutic fore-structuring of scientific research that keeps the interpretative openness (as opposed to both essentialist determinism and teleological finalization) of the domain. The hermeneutic fore-structure "works" against the attempts at codifying a complete and ultimate cognitive structure of a scientific domain. It constantly reveals possibilities for domain's further articulation.

The hermeneutic fore-structure of domain's articulation can be thematized in several respects. One of them, which I am going now to exemplify, is the way in which the projected horizon of research possibilities allows or precludes the existence of certain theoretical objects. In 1961 Peter Mitchell introduced in the domain of enzymology and bioenergetics a theoretical scenario for the coupling of respiration and ATP synthesis. It is designed to provide explanation of the energetic resources for the phosphorylation step from ADT to ATP. On Mitchell's account, the coupling of respiration and ATP synthesis is mediated by an electrochemical gradient of protons across the mitochondrial membrane. The emphasis was placed on the causal link between the flow of electrons through the respiratory chain enzymes and the translocation of protons across the inner mitochondrial membrane. This account was deliberately forged as an alternative to the chemical mechanism of the oxidative phophorylation which appeals not to anisotropic flaws but to enzyme-bound chemical compounds. ${ }^{14}$

In fact, Mitchell came to the scenario of "chemiosmotic coupling in energy transduction" (so the technical expression he proposed) in following a particular scientific practice-the one of drawing analogies. In his case, the analogy was between the osmotic translocation reactions (for instance, the coupling of phosphate translocation against arsenate translocation) and the enzyme catalysed group-transfer reactions. ${ }^{15}$ There was nothing unusual in pursuing this thoroughly conventional scientific practice. Mitchell's scenario was by no means an exotic hypothesis since the chemiosmotic coupling was known as early as the 1930 when a research group reported on

${ }^{13}$ Since the hermeneutic fore-structure of scientific research is to be circumscribed neither in the context of justification nor in the context of discovery, the studies into the interpretative articulation of scientific domains has to be placed in a "context of constitution" (after the hermeneutic-phenomenological concept of constitution) that is completely independent of the traditional context-distinction. (See Ginev 2006.)

${ }^{14}$ On two nice philosophical reconstructions of Mitchell's research program and its experimental verifications, see (Weber 2002) and (Prebble 2001).

${ }^{15}$ See in this regard (Mitchell 1972). 
chemiosmotic coupling in group-transfer reactions in studying the role of the NAD coenzyme. Nonetheless, until the mid 196os the "chemiosmotic mechanism" of energy generation implied by Mitchell's scenario remained without resonance in scientific community. This mechanism brings into play theoretical objects like "the transmembrane electrochemical potential powering the enzyme of the mitochondrial ATPase", "the anisotropic enzymes requiring two aqueous phases separated by a membrane", "the phosphorylation reactions driven by proton-motive force", and most of all "the electrochemically based vectorial metabolism" (i.e. metabolism whose catalytic systems are distinguished by a spatial orientation of the reactions' dynamics). These are objects which the domain's hermeneutic fore-structure at the beginning of 1960 s does not project as possible entities (i.e. entities whose existence can be authenticated through domain's articulation).

To put it differently, at the beginning of 196os the established configuration of practices has not been projecting such research possibilities of domain's articulation whose appropriation and actualization would have been authenticated the existence of Mitchell's theoretical objects. Within the interrelated scientific practices the research community did not have the foresight, fore-having, and fore-conception about these objects. They were simply "impossible objects" within the established configuration of practices entitled to unfold how mitochondria generate useful energy in the form of adenosine triphosphate. Among the practices involved in that configuration were practices of experimental identification of high-energy intermediates that supposedly are capable of transferring a phosphate group in the formation of ATP from ADP, practices of fractionation shedding light on the energetic aspect of protein synthesis; amendments of the mathematical plots of enzyme kinetics, elaborations on formalism about the bioenergetic functions of mitochondria, constructing of experimental systems for disclosing new causal links in the biochemistry of respiration, and so on. All of these practices were designed to provide evidence and confirmation of the chemical theory of ATP synthesis. Accordingly, the configuration of practices projected horizon of possibilities for identifying a purely chemical mechanism of the oxidative phophorylation based entirely on high-energy intermediates in the formation of ATP. There was no room for theoretical objects related to the ontological assumption that the mitochondrial bioenergy is due to an electrochemical gradient of protons.

It was the change of the configuration of practices that made possible the spaces of representation/reading of vectorial metabolism of respiration. Based on the assumption that protons might be directly involved in the oxidative phosphorylation, several laboratories undertook experiments on proton gradients. In addition, more precise methodic of establishing the lo- 
cation of phosphorylating enzymes was introduced. Later on the practice of measuring protons translocation in respiring mitochondria came on the scene. As Marcel Weber (2002) makes it clear, thanks to this practice several predictions made by Mitchell's initial theory were confirmed. Though many of the experimental results obtained explanations also in the framework of the chemical theory, the confirmation through independent tests provided a rationale for legitimizing (at least some) of the theoretical objects in whose existence the supporters of the chemiosmotic theory believed. However, much more important was the new hermeneutic fore-structure provoked by the (relatively small) change of the configuration of practices. New possibilities for doing research became projected, including possibilities whose appropriation was in line with the assumptions of the anisotropic flows of energy and the vectorial metabolism. The theoretical objects envisaged by chemiosmotic theory were significantly specified and "inscribed" on the horizon of new possibilities. Also a "conversion to the belief in Mitchell's objects" took place. Whole laboratories launched research programs inspired by the belief in these objects. As a result, several research groups started to articulate the domain of enzymological bioenergetics in accordance with possibilities for instantiating the chemiosmotic mechanism via data-models.

\section{Approaching the Concept of Characteristic Hermeneutic Sit- uation}

Up to this point I spoke of research situations as configurations of scientific practices distinguished by readable technologies. From the viewpoint of philosophical hermeneutics, however, each collective cognitive process takes place in a hermeneutic situation. Scientific research does not make an exception. It always takes place in a characteristic hermeneutic situation, i.e. in a situation in which the triad of fore-sight, fore-having, and foreconception becomes specified in a certain manner. ${ }^{16}$ This specification is to be tentatively explicated as a (relatively stable) tendency in the domain's articulation.

The hermeneutic fore-structure is not something that is statically pregiven to the dynamics of scientific research. In each configuration of scientific practices the unity of fore-having, fore-sight, and fore-conception opens itself in a specific manner. The hermeneutic fore-structure (as possibilities of seeing, having, and grasping domain's empirical and theoretical

\footnotetext{
${ }^{16}$ Thus, one has to discriminate between the particular situations of a research process and the hermeneutic situation which characterizes the ongoing interpretative articulation invoked by that process.
} 
articulation) does not have a being-in-itself that might be separated from the changing configurations of scientific practices. Nevertheless, there is a general characteristic of how a domain's cognitive structuring gets constantly embedded in an open (and changeable) hermeneutic fore-structure. This general characteristic expresses itself as a tendency in the reading process that brings into being scientific objects distinguished by way of their contextual representation and the degree to which they can be de-contextualized by practices of idealization. The balance between contextualization and decontextualization which persists in the articulation of a domain of scientific research I call a characteristic hermeneutic situation. From the very outset the scientific domain becomes disclosed (for a further articulation) in such a situation. Intuitively speaking, the research process as a process of reading is characterized by conjugated dimensions of (re)contextualization and decontextualization of what gets constituted as objects of inquiry. The second dimension strongly hinges on the formal codification (by means of mathematical idealizations) of the objects. They exist as codified entities in mathematical space-time. All readable technologies employed in the research process are to be isolated from the outcome of this process. As a consequence, the objects of inquiry are completely de-contextualized-an extreme case that can be only approximated via strong practices of idealization.

The balance between de- and re-contextualization of scientific objects depends first and foremost on the separability degree of the readable technologies being implemented from what gets read. The more these technologies are isolable from the reading process, the stronger is the tendency to de-contextualization. The opposite case is when the readable technologies become "integral element" of the objects of inquiry. In this case, if different readable technologies provide alternative spaces of representation, one cannot avoid the use of a version of uncertainty principle in order to get a coherent theoretical constitution of the objects. Yet the balance between de- and re-contextualization needs a stable point of reference. In my view, it is the natural ontological attitude that serves the function of such a point. It tacitly sets limits of reasonable de- or re-contextualization in reading/representing objects of inquiry.

In reaching this conclusion, I touch on the issue of the formation of local epistemological positions. Leaning on this reasonability, one defines norms and criteria for assessing domain's articulation, thereby paving the way to the formation of an epistemological position. Reasonability and practical rationality are intrinsic properties of the natural ontological attitude. In scientific research they make possible the resilience in implementing readable technologies and arranging appropriate spaces of representation. Reasonability and practical rationality manifest the fore-having, fore-sight, and 
fore-conception of reading/representing in a given research situation. The anticipations and expectations related to the interpretative fore-structuring license a kind of proto-normativity that accompanies reasonability and practical rationality. Within the tendency launched by a characteristic hermeneutic situation the proto-normativity gets stabilized and transformed into explicit epistemological normativity. On this scenario, the reasonability of the natural ontological attitude does not vanish with the formation of local epistemological positions. It becomes rather specified with regard to the balance between de- and (re)contextualization.

Now the reversible assertion is also valid: The tendency of specifying a local epistemological position within the interpretative fore-structuring of domain's articulation is the characteristic hermeneutic situation of that articulation. This tendency persists in the changing configurations of scientific practices. The local epistemological position is in a constant process of formation since it is constantly fore-structured by the interpretative appropriation of projected possibilities. In this process of formation of the characteristic hermeneutic situation takes shape as threefold balance between (a) the proto-normativity of interpretative fore-structuring and the explicit epistemological norms and criteria; (b) the contextualization and de-contextualization of scientific objects; and (c) the interpretative openness and model-semantic determination of domain's conceptual-formal structures.

Let me recapitulate the considerations of this section. In scientific research the circulative nexus of understanding and interpretation takes the form of a hermeneutic fore-structure of a domain's structural, conceptual, and experimental articulation. In each particular research situation (configuration of scientific practices as readable technologies) the research process is characterized by fore-sight, fore-having, and fore-conception of what becomes articulated as an outcome of appropriated possibilities. It is this hermeneutic context in which I would like to place now the concept of the natural ontological attitude. More specifically, I am going to claim in the next section that NOA is the interpretative attitude toward what gets disclosed by domain's horizon of possibilities. When Fine reaches the conclusion that neither the realist nor the anti-realist can stand outside the world, and that they cannot survey some area off the playing field and mark it out as what the game is about, he actually affirms the priority of the state of being-in-the-world over the disentangled epistemic position that represents the "external world". The natural ontological attitude is the interpretative stance of orienting practically within the world. In other words, the natural ontological attitude is the base for all kinds of "practical interpretation" that is taken for granted by common sense epistemology and the philosoph- 
ically elaborated epistemologies. Interpretative stance in practical orientation within the world amounts to choosing and appropriating possibilities of how to comport contextually. In this regard, the natural ontological attitude as interpretative stance "finds" the world in the first place as a horizon of possibilities. Homely true is the practically oriented interpretative deliberation within the world that articulates the world in a pre-epistemological way. This interpretative deliberation does not get lost or eliminated in scientific research. It is rather fore-structuring the results of this research. Scientists are working in their domains of research by being committed to the prescientific (natural) interpretative stance.

\section{Rereading NOA}

According to Fine, the death of realism was hastened by the victory of Bohr's non-realist philosophy of quantum theory over Einstein's philosophical realism. The further development of the controversy about the interpretation of quantum mechanics called into question-so Fine's argument goes-the very debate between realism and anti-realism. The extra-theoretical relation of "being approximately true" which the realist immerses between scientific theories and the world is neither to be proved nor to be refuted. It simply must be rejected as a kind of metaphysically hypostatized essentialism. The anti-realist advocacy of essentialism consists in postulating global intrinsic features of science's cognitive organization. Empirical adequacy and usefulness are examples of such features. Though the anti-realist does not immerse an extra-theoretical relation between theories and the world, she still (due to the postulation of intrinsic features) commits to an external position to scientific enterprise. In repudiating the realist's inflation of metaphysics, the anti-realist undertakes an inflation of epistemology and/or semantics.

Fine cogently reveals the close connection between philosophical externalism and metaphysical/cognitive essentialism. ${ }^{17}$ In his later workroughly, the papers from the last two decades-he is not so much preoccupied with NOA conception. Yet the issue of avoiding philosophical externalism/globalism continues to be a leading theme for him. ${ }^{18}$ To be sure, his phi-

${ }^{17}$ See in this regard Rouse's (1996, 90-100) interpretation of Fine's conception.

${ }^{18}$ For a nice illustration of this development see (Fine 2009). In this paper one is to read the following statement: "In the context of the realism debates a demand to explain the success of science is familiar. By now one would have thought it also suspicious, since the endless run-around pursued in those debates makes it clear that, in this context, attending to the demand for explanation leads nowhere philosophically useful. In view of that it is hard to see why a global demand for philosophical explanations, a demand with respect to all scientific practice, should even be a player in coming to terms with our philosophical work. Talk of goals here seems a thinly disguised way of imposing a philosophical agenda without providing any plausible rationalization for why it would be reasonable or fruitful 
losophizing "from the inside of science" echoes important moments of Carnap's discussion of the "internal questions". These are the questions which can be only formulated within science's linguistic frameworks, thereby becoming distinguished from the metaphysical "external questions". Likewise Fine is convinced that the external philosophical debate over realism does not concern questions that can be settled by developments of the sciences, no matter how successful science may be.

Notoriously, Fine refers to NOA also as a "core position" that counsels us to accept the results of science "on a par with more homely truth" without appealing to more esoteric epistemological considerations and justifications. Thus, the core position is both independent of all positions within the realism-debate, and a common prerequisite of these positions. A realist or an anti-realist position becomes emancipated when one adds on to the core position ontological doctrines and epistemological analyses. By contrast, the core position mediates between the poles of realism and anti-realism without incorporating metaphysical additives. On this account, anti-realists add on to the core position pragmatic, conventionalist, or instrumentalist conceptions of truth as well as several methodological strictures. What realists add on in the first place is a strategy for avoiding the elimination of the conception of truth as correspondence with the world, (sometimes) arguments for a separation of realism from any semantic doctrine (including referential semantics), and (again in some cases) meta-narratives of how science's historical progress approximates the fundamental truths about the external world.

By advocating (metaphysical or cognitive) essentialism, one works out the doctrines of realism and anti-realism as "unnatural attitudes". Fine's conception is most of all a "minimalist" (i.e. a radically anti-essentialist) philosophy of science that operates on the model of immanent literary criticism. Fine $(1984,41)$ goes on to draw the attention to another parallel: In the same manner in which minimalist art serves the function of an immanent criticism of art, the conception of NOA operates as local criticism within science's own leeway. The minimalist philosophical intervention in this leeway should be instrumental in settling long-standing methodological debates in science-a possibility typically illustrated by Fine's excellent studies in the history of quantum mechanics. According to him $(1996,254)$, what one needs is a non-realist immanent criticism for post-realist times. The minimalist philosophy of science sketches out supposedly the premises of such a criticism. To have a natural attitude toward the world amounts to interpreting the world in a "natural manner", i.e. in a manner that is presumably "homely true" for all agents dealing instrumentally with what is ready to 
hand within the world.

Though Fine does not lay an explicit claim, he tacitly admits the cultural universality of the core position. This tacit admission hinges on the (presumably anthropologically) universal credence in primary (homely) truths that are not in need of epistemological justifications. More specifically, human beings are always getting knowledge against the background of "always already accepted" primary truths. They do not call into question these truths when they (in admitting additional ontological assumptions) are elaborating on more sophisticated epistemic constructions designed to disclose "nonfamiliar truths". This means that they have an understanding of the world as being articulated in accordance with these truths. By changing fundamentally the understanding of the world, science appeals to much more articulated images of reality corresponding to science's objective truths. However strong the divergence between the articulation (against the background of primary truths) and science's images of reality might become, the construction of knowledge in scientific research keeps necessarily presupposing this background. In this regard, the latter informs the acceptance of science's results on a par with always already accepted truths, which is Fine's basic point. The aforementioned universality of the core position (i.e. the position which takes for granted the background of primary truths) concerns in the first place the nexus of understanding and interpretative articulation (as this was discussed in the previous section). It is this nexus that crosses the borderline between pre-scientific (practical) experience and the scientific research.

In the early 1980 s Fine developed the conception of the natural ontological attitude (to a certain extent) as a radicalization of Rorty's undoing epistemological representationalism and foundationalism. (This radicalization is also intimately related to Fine's minimalist image of philosophy of science.) The natural ontological attitude is not a contemplative attitude. The very expression does not designate a static relationship between the knowing subject (as a passive observer) and the "external world" out there. A constitutive moment of the "nature" of human existence is the practical attitude toward the world. By implication, the natural ontological attitude characterizes the human agents' practical involvement in the world. The natural ontological attitude is an active stance that is not isolable from the stream of changing configurations of practices that provide the access to the world. It is a stance of practitioners who "face" the world through their practices. ${ }^{19}$ This is why

${ }^{19}$ On this account, the world is articulated interpretatively by practitioners within ongoing contextual transformations of the horizon of possibilities. Being-in-the-world is the expression used in philosophical hermeneutics for this state of affairs. The contact with entities is always mediated by practices, whereby the primary status ascribed to the enti- 
Fine goes on to argue that his conception is closely allied to Rorty's epistemological behaviorism. ${ }^{20}$

Now, let me try to derive some more consequences from assigning to NOA the status of an interpretative attitude that precedes the formation of (local and contextual) epistemological positions in scientific research. It should be emphasized in a tentative manner that the expression "NOA precedes the formation" in this formulation is neither to be related to a causal determinism, nor to be understood in a literary temporal sense. The expression has rather much to do with a projection of interpretative fore-structure that contextualizes a formative process. It is this thesis that promotes the search for a convergence between the conception of NOA and the hermeneutic theory of scientific research as sketched out in the preceding section.

To reiterate, NOA is the interpretative-practical attitude toward the world. It is "natural" because this attitude takes place always already within the world of familiar and routine practices. Accordingly, the world is constantly interpreted by human beings as practitioners (in particular, as practitioners doing "normal" (in Kuhnian sense) scientific research). In stressing this aspect, one has good reasons to oppose Alan Musgrave's celebrated realist construal of NOA. Since the referential way of treating truth is built into the core position (and the semantic conception of truth is a version of the common-sense correspondence theory of truth) - so this construal goesNOA is the starting-point for defending realism in the philosophy of science. The epistemological minimalism committed to a common-sense correspondence theory of truth is a kind of minimal realism. In Musgrave's account, there is no one core position for realists and anti-realists to accept. Indeed, there is no such position if one assumes that it consists of elementary epistemological statements that express an embryo form of realism. But one is not obliged to accept such an assumption. In treating NOA as contextually specified interpretative stance toward the world, one is not to admit that it is determined by elementary epistemological statements. Moreover, if such a kind of determinism takes place, it would imply a version of essentialism that Fine repudiates. By contrast, the construal of NOA as interpretativepractical attitude lays emphasis upon its capability to contextualize in a pre-

ties within the world is not the status of independent objects, but the status of something ready-to-hand for practitioners. In the hermeneutic rereading of NOA I am suggesting, the pragmatic character of this attitude should be made to refer to the deliberative comportment in dealing with what is ready-to-hand. NOA is a "natural" (i.e. based on natural ontological assumptions) pragmatic interpretation of the world that takes place within the world. By being committed to this attitude, practitioners appropriate possibilities to dealing with entities in the changing contexts of being-in-the-world. Accordingly, one faces the world as a pragmatic potentiality for being.

${ }^{20}$ Rorty (2007) in his turn announced Fine for his favored philosopher of science. 
epistemological manner the formation of epistemological positions liable to assess decisions made in the respective contexts.

To sum up, in treating NOA in terms of a primitive epistemological position (i.e. as an epistemological position without philosophical additives), one fails to meet the critical arguments against the core position's independence. Yet there is also another option on offer-to assign to NOA a preepistemological status, thereby admitting that the characteristics of the interpretative attitude toward the world (as this attitude is established within the world) are at the same time premises for having local epistemological positions in scientific research. Because the natural ontological attitude is not a kind of proto-realist position, it is not correct to hold that realists can accept "the more homely true vision" of the world invoked by this attitude, but the anti-realists cannot. In fact, both of them accept it tacitly, specifying it (if they are working scientists and not philosophers) contextually. I think that this option is congruent with Fine's intentions, although he has never used the term 'pre-epistemological. ${ }^{21}$

In assigning a pre-epistemological status to NOA, one meets also another critical argument raised against Fine's conception-the argument of circularity. According to it, the supporter of this conception appeals to the same sort of judgment (and by implication, commits the same fallacy) which Fine ascribes to the realist, "who presupposes the truth-conferring ability of arguments to the best explanation in a meta-theoretical argument for the truth-conferring power of arguments to the best explanation in science" (Rouse 1988, 296). The defense of the view that the concept of truth is contextually situated requires a contextualist theory of justification. Though understood as a local position, the same kind of (realist) epistemological justification works again (in the defense of NOA) at the level of scientific research and at a meta-theoretical level. Thus, a (presumably) vicious circularity of epistemological justification-so the critical argument goes-is unavoidable in Fine's conception. This circularity does not come to the fore, however, if NOA is distinguished by a pre-epistemological status. Several considerations that support the ascription of such a status to NOA are to be found in Fine's work.

${ }^{21}$ In my view, the natural ontological attitude is not a common-sense epistemology as well. Like professional philosophy's "esoteric epistemologies", the common-sense epistemology presumes an interpretative articulation of the world. Through this articulation the agents within the world are anticipating the truthfulness of the content of statements about particular individuals, properties, relations, processes, and so forth in whose existence the agents (guided post festum by common-sense epistemology) believe. In being anticipated in such a manner, the common-sense epistemology is capable to sanction ordinary referential semantics, and commit the practitioners within the world to the existence of the individuals, entities and events referred by the experiential statements. 
When Fine repudiates the "realist metaphysical picture of the world", he pinpoints three interpretative characteristics of the attitude toward the world. He discusses them with regard to the way in which they mediate the "access" to the world. ${ }^{22}$ The first characteristic is the contextual relevance and validity of an epistemological position. On Fine's account, the commitment to a monolithic epistemological stance should be rejected since scientists follow different networks of aims, norms, standards and criteria in the different contexts of their research work. Science is not an epistemologically unified enterprise, determined by a global normative position. Accordingly, scientists' attitude toward the world is predicated on an interpretative resilience that requires a local, nuanced, and contextual approach to the constitution of a meaningful access to the world through scientific practices. ${ }^{23}$ Stressing that due to the contextual-interpretative access to the world the epistemological positions of scientists are predicated on conditional relevance is Fine's strongest argument against metaphysical globalism proffered by both the realist and the anti-realist.

The second interpretative characteristic of the attitude toward the world is the interactive reciprocity in dealing with the entities in the world. The entities which we causally interact with-so Fine's argument goes-are not independent of us. In interacting with entities, we are always embedded in contexts of interaction, whereby the entities become entangled with our practices. One has to add to this formulation that our practices make the world a meaningful totality of practical entities, projected upon the horizon of their possible uses.

The third interpretative characteristic is the "contamination" of the information about the objects within the world. It involves unavoidably information about the interacted-with things. In other words, the scientific information about the objects of inquiry "out there" is always contaminated with information about the contextual-practical interaction with these objects. Since the objects of inquiry are contextualized by configured scientific practices, the "contamination" with contextual contingencies is not to be dispelled from the research process as well.

Despite the discussion of the three interpretative characteristics, Fine's concept of the "access to the world" remains insufficiently scrutinized. In my view, the conception of NOA is to be further developed by having recourse to the interpretative premises of contextual resilience, interactive reciprocity, and cognitive "contamination" which are underlying (not the global epistemological positions involved in the realism-debate, but) the local positions stemming out contextually of scientists' research work. An important clue

${ }^{22}$ See, in particular, (Fine 1986).

${ }^{23}$ See in this regard (Fine 1991). 
about the further development is to be found in Musgrave's report on a conversation he has had with Fine in 1987. It has been suggested to Musgrave by that conversation the following point: Since the natural ontological attitude is not committed to actual (non-scientific or scientific) entities, one should attribute to the NOA a "complete philosophical know-nothing-ism" (Musgrave 1989, 53). But just because NOA is not ontologically committed to actual presence in the world out there, it commits to all possibilities whose actualizations might take place. One might manage to let science speaks for itself, if and only if one does not burden science with a commitment to the existence of entities as a pure (actual) presence. Guided by the NOA, scientific research is constantly projected upon possibilities that never become subordinated to an ultimate (cognitive, metaphysical, or whatever) aim.

The view that the access to the world is to be only achieved within a projected horizon of possibilities is implied by the primacy of the characteristics of interpretative resilience, interactive reciprocity, and "contamination". ${ }^{4}$ Thus, the concept of the "access to the world" is one that traffics in certain ontological assumptions that assign to the potentiality-for-being a priority over the being-as-a-pure-presence. This construal sheds light, in my view, on the ontological commitment of NOA. Contrary to Rorty (2007, 144), I think that the notion of ontological commitment is not a notion that the conception of NOA could get along without. NOA is committed to the world as it is revealed by the primary homely truths. But (in line with Fine's intentions) the notion of ontological commitment should be illuminated not by means of a realist metaphysics. It is a notion that has to be circumscribed by a hermeneutic doctrine of the potentiality-for-being.

This further development (and reformulation in the hermeneutic context sketched out in the preceding section) of the NOA conception sharpens its arguments against the teleological picture's of science depicted by the external philosophies whose metaphysical inflation consists in the first place in imposing an ultimate aim of science. Philosophy of science ought to dispense with teleological frameworks in which to set the research process. In line again with Fine's elaborations, one is to state that scientific research in its diversity of contexts and situations shows its multiple- and mini-aims daily. In placing the conception of NOA in a hermeneutic context (that avoids any superimposition of a priori explanation) one becomes provided with a rationale for restraining from searching for authorities that allegedly authenticate

${ }^{24}$ I am speaking here of 'primacy' in the sense that they are not "derivable" from a primary referential stance toward the world. At this point, my reformulation of NOA runs in contrast to Fine's original view. Fine insists on the inscrutability of such a stance. It is unclear how he reconciles this insistence with his treatment of interpretative resilience, interactive reciprocity, and "contamination" as constituting the access to the world. 
science. Scientific research has neither external nor internal authorities, but it is constantly interpretatively fore-structured. For NOA crosses the border between pre-scientific "interpretative deliberation" and science's interpretative articulation, it might be taken into consideration in two different respects.

On the one hand, NOA is a primary interpretative attitude within the world on which all kinds of scientific research are grounded. ${ }^{25}$ The minimalist core position which involves "natural" ontological assumptions (corresponding to the more homely truths) should be open to the integration of new assumptions when one articulates a domain of research. The natural ontological attitude does not remain unaffected when operating in domain's articulation. Otherwise the NOA would have prevented one from disclosing possibilities whose appropriation contradicts the core position's assumptions. In this regard, one can concede that the NOA undergoes various extensions and enrichments in the reading process of scientific research. These are in the first place extensions of the belief in what exists. For the community articulating a domain of research the new entities are no less "natural" than the entities (individuals, processes, events, and so on) one has in the pre-scientific natural ontological attitude. This statement does not diverge from Fine's claim that the "working scientists" do not add on to the core position realist or anti-realist doctrines. The extensions and enrichments I am speaking about have to do only with the domain's articulation. They are neutral with regard to the realism debate. Furthermore, any enrichment of NOA with new ontological assumptions is an intrinsic event of a domain's three-dimensional articulation. It does not demand a superimposition of an external position on the natural interpretation of the world taking place in human agents' everyday practices. There is no rupture in the transitions from these practices to specialized practices of science's research work. The intrinsic continuity does not require an external philosophical explanation.

On the other hand, NOA is an interpretative attitude within scientific research that plays a crucial role in the specification of a hermeneutic forestructure as a characteristic hermeneutic situation. The NOA mediates the transformation from the proto-normativity of interpretative fore-structuring to the explicit epistemological norms, rules and criteria. In the way of appropriating possibilities of doing research scientists make explicit the protonormative fore-having, fore-sight, and fore-conception as contextual norms

${ }^{25}$ This would be a quasi-Husserlian scenario of philosophical investigation of science. As already indicated, Fine rejects a reinterpretation of his conception in Husserlian terms. Yet the possibility of such an investigation can be designed in a more hermeneutic way that has little to do with Husserl's critique of science through unfolding in a transcendental manner the world of the natürliche Einstellung. 
and criteria. More specifically, the NOA as entangled with a hermeneutic fore-structure of appropriating possibilities for doing research "assists" (due to its reasonability) the transformation of the proto-normative forehaving, fore-sight, and fore-conception into local norms and rules of deand re-contextualization of scientific objects. This transformation is a necessary moment for endowing the tendency of specifying the hermeneutic fore-structuring as a characteristic hermeneutic situation with a normative force. Yet NOA does not remain indifferent to the result of the specification. Placed in a characteristic situation, it becomes a normative attitude too. Being in such a situation NOA's reasonability vindicates or discards a scientific community's views and visions of truth, objectivity, completeness, conceptual simplicity, etc. when this community makes particular epistemic decisions. Thus, in a characteristic hermeneutic situation NOA opens the way (by regulating the transformation of proto-notmativity into explicit norms and rules) to local epistemological positions.

It is the hermeneutic rereading of NOA that opens the avenue to a dialogue between the methodologically shaped hermeneutics and the kinds of non-representationalist and non-foundational epistemology. No doubt, it is a dialogue that promises new perspectives in the philosophy of science and science studies. Yet more important than these perspectives is the chance for a genuine exchange between the traditions of analytical and Continental philosophy in the post-science-wars era. It is this exchange that should weaken the traditional dichotomies (trying eventually to get rid of them) and bridge the gaps brought into existence by the mutual misunderstanding. Paraphrasing Fine, what one needs is a philosophical identity of science for a post-war time.

\section{Bibliography}

Brading, K. (2011). Structuralist approaches to physics: Objects, models and modality, in A. Bokulich and P. Bokulich (eds), Scientific Structuralism, Springer, Dordrecht, pp. 43-66.

Eger, M. (2006). Science, Understanding and Justice, Open Court.

Fine, A. (1984). The natural ontological attitude, in J. Leplin (ed.), Scientific Realism, University of California Press, Berkeley, pp. 83-107.

Fine, A. (1986). natural attitudes: Realist and instrumentalist attachments to science, Mind 95: 149-179.

Fine, A. (1991). Piecemeal realism, Philosophical Studies 61: 79-96. 
Fine, A. (1996). Shaky Game: Einstein, Realism, and the Quantum Theory, University of Chicago Press, Chicago.

Fine, A. (2009). Science fiction, Philosophical Studies 143: 117-125.

French, S. and Ladyman, J. (2011). In defence of ontic structural realism, in A. Bokulich and P. Bokulich (eds), Scientific Structuralism, Springer, Dordrecht, pp. 25-42.

Ginev, D. (1997). A Passage to the Hermeneutic Philosophy of Science, Rodopi, Amsterdam.

Ginev, D. (2006). The Context of Constitution: Beyond the Edge of Justification, Springer, Dordrecht.

Ginev, D. (2008). Cognitive existentialism, Iyyun: The Jerusalem Philosophical Quarterly 57: 227-242.

Ginev, D. (2011). The Tenets of Cognitive Existentialism, Ohio University Press, Athens.

Heelan, P. (1983). Natural science as hermeneutic of instrumentation, Philosophy of Science 50: 181-204.

Heelan, P. (1989). Yes! there is a hermeneutics of natural science: A rejoinder to Markus, Science in Context 3: 477-488.

Heelan, P. (1998). The scope of hermeneutics in natural science, Studies in the History and Philosophy of Science 29: 273-298.

Kockelmans, J. (1993). Ideas for a Hermeneutic Phenomenology of the Natural Sciences, Kluwer, Dordrecht.

Mitchell, P. (1972). Chemiosmotic coupling in energy transduction: A logical development of biochemical knowledge, Bioenergetics 3: 5-24.

Musgrave, A. (1989). NOA's ark-Fine for realism, Philosophical Quarterly 39: $383-398$.

Prebble, J. (2001). The philosophical origins of Mitchell's chemiosmotic concepts, Journal of the History of Biology 34: 433-460.

Rheinberger, H.-J. (1997). Toward a history of epistemic things: Synthesizing proteins in the test tube, Stanford University Press, Stanford.

Rorty, R. (2007). A pragmatist view of contemporary analytical philosophy, Philosophy as Cultural Politics. Philosophical Papers, Cambridge University Press, Cambridge, pp. 133-146.

Rouse, J. (1988). Arguing for the natural ontological attitude, in J. Leplin, A. Fine and M. Forbes (eds), PSA: Proceedings of the Biennal Meeting of the Philosophy of Science Association, University of Chicago Press, Chicago, pp. 294-301. 
Rouse, J. (1996). Engaging Science: How to Understand Its Practices Philosophically, Cornell University Press, Ithaca.

van Fraassen, B. (1976). To save the phenomena, Journal of Philosophy 73: 623-632.

van Fraassen, B. (1980). The Scientific Image, Oxford University Press, Oxford.

Ward, R. (2001). Peirce and politics, Philosophy and Social Criticism 27: 6790.

Weber, M. (2002). Incommensurability and theory comparison in experimental biology, Philosophy and Biology 17: 155-169. 